\title{
Modulation of T Cell Activation in Obesity
}

\author{
Morin Stéphanie O, Poggi Marjorie , Alessi Marie-Christine, Landrier Jean-François \\ , Nunès Jacques A
}

\begin{abstract}
AbstractSignificance: Immune T cells are present in adipose tissues (AT), and the stoichiometry of the different $\mathrm{T}$ cell subsets is altered during diet-induced obesity (DIO). $\mathrm{T}$ cells contribute to the early steps of AT inflammation during DIO.Recent Advances: Many factors could potentially be responsible for this altered pro-inflammatory versus antiinflammatory $\mathrm{T}$ cell balance.Critical Issues: $\mathrm{T}$ cells are potentially activated in AT, which vitamin $\mathrm{D}$ might contribute to, as will be discussed in this article. In addition, we will review the different possible contributors to T cell activation in AT, such as the CD28 and CD154 T cell costimulatory molecules in AT.Future Directions: The potential antigen presentation capacities of adipocytes should be further investigated. Moreover, the properties of these AT resident (or migrating to AT) T cells must be further assessed. Antioxid. Redox Signal. 26, 489-500.
\end{abstract}

\section{Introduction}

"Globesity" is a term used to qualify the growing global epidemic of overweight and obesity in both developed and developing countries (56). Obesity is a major risk factor for a number of chronic diseases that are associated with metabolic disorders such as diabetes, as well as for cardiovascular diseases (41). Additionally, obesity is associated with an increased risk of cancers derived from different tissues (76). Finally, obesity increases the risk of autoimmune diseases (89), and the susceptibility to the bacterial or viral infections due to a loss of control by the immune system (46). In fact, obesity is associated with both systemic inflammation and the recruitment of pro-inflammatory immune cells into white adipose tissue (AT) (17).

Major cellular features of AT are altered during obesity, such as adipocyte hypertrophy and macrophage-mediated inflammation. The macrophage compartment can reach up to $60 \%$ of visceral adipose tissue (VAT) immune cells in obesity. Macrophages can be polarized toward an M1 or an M2 phenotype. Macrophages in obese tissue are mostly M1 macrophages (also known as classically activated macrophages) that secrete pro-inflammatory cytokines such as interleukin (IL)-6 and tumor necrosis factor (TNF)- $\alpha(21,63,65)$. These cells correspond to the first immune cell populations identified in the inflammation process $(92,96)$. This proinflammatory macrophage population can be further subdivided based on the expression of genes regulating lipid metabolism (50). These pro-inflammatory macrophages, essential actors of the AT inflammation, are considered to be innate immune cells. However, it is well known that adaptive immune cells such as $\mathrm{T}$ cells also have a critical role in the early stages of inflammatory processes $(37,63)$.

In this article, we will discuss the role of the different inflammatory and regulatory $\mathrm{T}$ cells found in AT in diet-induced obesity (DIO). The role of cosignaling molecules in T cells, which are extensively studied for cancer immunotherapy strategies, will be reported in the context of DIO. In addition, some factors that are likely to affect T cell activity in the AT (as 
fat T cells) will be discussed, such as AT inflammation modulators, vitamin D, or hypoxic AT conditions. Altogether, this knowledge could be exploited to treat metabolic disorders in obese patients by targeting $\mathrm{T}$ cells.

\section{T Cells and Obesity-Related Inflammation}

Three independent groups have highlighted the essential role of $\mathrm{T}$ cells infiltrating the visceral AT for the development of inflammatory processes during DIO or in genetic obese mouse models $(34,63,93)$. A schematic view of T cell alterations in AT has been illustrated in several reviews $(17,21,83)$. In extracts of visceral AT of lean mice, T cells constitute around $10 \%$ of the stromal-vascular fraction (83). The accumulation of T cells in AT in healthy women increased with the body mass index (31). The number of T cells is increased in VAT of both obese humans and mice $(31,77)$.

In principle, this accumulation of $\mathrm{T}$ cells could be due to both proliferation of resident cells and recruitment of T cells into AT (31). The cell division of splenic CD8 ${ }^{+} \mathrm{T}$ cells was reported to be highly potentiated during a contact with epididymal AT from DIO mice, but not with AT from lean mice (63). In addition, some adipochemokines such as C-C motif ligand (CCL) 5, CCL5, or CCL20 are described as attracting T cells into AT $(29,31)$. The cytotoxic $\mathrm{CD}^{+} \mathrm{T}$ cell pool is involved in the pro-inflammatory response. However, for the $\mathrm{CD}^{+} \mathrm{T}$ cell pool, these cells can be divided into two major subsets: the regulatory $\mathrm{T}$ (Tregs) and the helper $\mathrm{T}(\mathrm{Th})$ cells. At least three Th subtypes can be further distinguished: Th1, Th2, and Th17. Th1 cells induced by IL-12 secrete pro-inflammatory cytokines such as interferon (IFN)- $\gamma$. Th2 cells induced by IL-4 secrete IL-4, IL-5, IL-10, and IL-13. Th17 cells induced by IL- 6 and transforming growth factor (TGF)- $\beta$ produce IL-17. Among these different CD4 ${ }^{+}$ T cells, Tregs with their immunoregulatory properties are clearly identified as antiinflammatory cells, and IFN- $\gamma / \mathrm{TNF}-\alpha$-producing Th1 cells are pro-inflammatory cells (13). Identification of other Th subsets such as Th9, Th22 cells is believed to have functions in tissue inflammation. Several lines of evidence are provided that similar to IL-17, IL-22 (produced by Th22 cell type) may contribute to a chronic pro-inflammatory state in AT of obese humans $(22,33)$.

All these $\mathrm{T}$ cells are characterized by the expression of a $\mathrm{T}$ cell antigen-specific receptor (TCR) $\alpha / \beta$ heterodimer. DIO-TCR $\beta$-deficient (TCR $\beta$ knock-out $[\mathrm{KO}])$ mice are protected against AT inflammation and insulin resistance. Moreover, a Th1 cell adoptive transfer into high fat diet (HFD)-fed TCR $\beta$ KO mice induces both AT inflammation and insulin resistance (48).

The balance between pro-inflammatory and anti-inflammatory $\mathrm{T}$ cells is modified during obesity-induced inflammation in VAT, the pool of pro-inflammatory T cells such as CD4 ${ }^{+}$ and $\mathrm{CD}^{+} \mathrm{T}$ cells is increased, and anti-inflammatory $\mathrm{T}$ cells such as Tregs are decreased in DIO [reviewed in Refs. $(17,32,73)$ ].

The presence of T cells in AT can be altered in many ways, including by diet. For instance, saturated fatty acids are generally associated with increased AT inflammation (85). Saturated fatty acid metabolism, which results in the activation of the nuclear peroxisome proliferatoractivated receptors (PPARs), is involved in many cell types that are present in AT to deliver pro-inflammatory outcome (24). One of the dietary components with anti-inflammatory properties is vitamin $\mathrm{D}$, which is involved in the control of both pro-inflammatory $\mathrm{T}$ cells 
such as Th1 and anti-inflammatory T cells such as Tregs. The role of vitamin D is discussed next.

\section{T Cell Differentiation, Obesity, and Transcription Factors Such as Vitamin D}

In the specific context of AT biology, vitamin D is strongly suspected to display a strong transcriptional activity in AT $(52,78)$, thus regulating adipogenesis, inflammatory pathways, or adipocyte metabolism, and it is, thus, suspected to have a beneficial role in obesity (51). Vitamin D mainly exerts its transcriptional effects by binding to the nuclear vitamin D receptor (VDR), a member of the nuclear receptor superfamily (10). More precisely, it is the active form of vitamin $\mathrm{D}$, calcitriol, or $1,25(\mathrm{OH})_{2} \mathrm{D}$ that binds VDR with high affinity (6). The VDR-1,25(OH) 2 D complex is associated with the retinoic acid receptor (RXR) (43), and the RXR-VDR-1,25(OH $)_{2} \mathrm{D}$ complex binds to DNA sites called vitamin D response elements (VDRE) in the promoter region of target genes (10). More than 1000 genes are under the direct or indirect regulation of $1,25(\mathrm{OH})_{2} \mathrm{D}$; these genes are involved in various physiological processes such as cell proliferation, differentiation, apoptosis, and angiogenesis (66). The expression of VDR has been detected in almost all human tissues (8), which means that all tissues can potentially be affected by $1,25(\mathrm{OH})_{2} \mathrm{D}$.

Interestingly, the VDR is expressed in almost all immune cells, including activated $\mathrm{T}$ and $\mathrm{B}$ cells, neutrophils, macrophages, and dentritic cells $(3,74)$. The fact that $\mathrm{T}$ cells express the VDR is consistent with the fact that this cell type is a vitamin D target, as previously demonstrated (2). Overall, vitamin D exposure induces a shift from a pro-inflammatory to a more tolerogenic immune state. The ability of vitamin $\mathrm{D}$ and especially its active form, calcitriol $\left[1,25(\mathrm{OH})_{2} \mathrm{D}\right]$, to inhibit $\mathrm{T}$ helper proliferation, differentiation and to modulate cytokine production is established $(54) .1,25(\mathrm{OH})_{2} \mathrm{D}$ is known to lead to a shift from Th1 to Th2 phenotypic subset of T cells, with Th1 being responsible for pro-inflammatory cytokine secretion (TNF- $\alpha$, IFN- $\gamma$, IL-2) and Th2 being associated with more anti-inflammatory secretion (IL-3, IL-4, IL-5, IL-10) (71). 1,25(OH) 2 D was also shown to inhibit the transcription and production of IL-17 by Th17 subpopulation (44). Finally $1,25(\mathrm{OH})_{2} \mathrm{D}$ enhances the suppressive activity of the regulatory T cells (Tregs), which reduced inflammatory state (98). Altogether, these data support that vitamin D, and especially $1,25(\mathrm{OH})_{2} \mathrm{D}$, displays a strong immunomodulatory effect on $\mathrm{T}$ cells.

Data regarding the specific effect of vitamin $\mathrm{D}$ or $1,25(\mathrm{OH})_{2} \mathrm{D}$ on AT-resident T cells are scarce. We recently reported that vitamin D supplementation in mice submitted to HFD reduces the relative quantity of T lymphocytes in AT as well as CD3 mRNA levels in the fat pads of these mice (45). Interestingly, vitamin D supplementation also strongly inhibits the expression and secretion of a large range of chemokines that are known to be upregulated by metabolic inflammation linked to obesity $(38,87)$. Such an effect could constitute explain the decrease in T cell quantity in supplemented mice, since chemokines such as CCL5 and CCL20 are involved in T cell migration (39). However, we cannot exclude that vitamin D supplementation [via the production of $1,25(\mathrm{OH})_{2} \mathrm{D}$ ] inhibits $\mathrm{T}$ cell proliferation in AT as was previously reported in vitro (54). The effect of the vitamin D supplementation on specific $\mathrm{T}$ cell subsets has not yet been investigated. This point would require further investigations to establish the precise effect of vitamin D supplementation on T cell phenotyping.

The active form of vitamin $\mathrm{D}$, as a component of a transcription factor complex, is involved in T cell differentiation $(44,71,98)$. However, in the general context of $\mathrm{T}$ cell differentiation, many transcription factors should be considered as master transcription factors, including $\mathrm{T}$ - 
bet, GATA3, ROR $\gamma \mathrm{t}$, and Foxp3 for Th1, Th2, Th17 cells, and Tregs, respectively (100). In the context of obesity, it would be also important to mention another type of transcription factors corresponding to PPARs. These proteins that are expressed in AT are key regulators of lipid metabolism and can be detected in T cells, such as PPAR- $\gamma$ (19). Furthermore, the ATresident Tregs expressing PPAR- $\gamma$ are involved in the control of AT inflammation and insulin resistance (16). Altogether, well-established networks of transcription factors involved in $\mathrm{T}$ cell differentiation and cell activation (100) should be further reviewed in AT-resident T cell subsets.

\section{T Cell Activation and Obesity-Related Inflammation}

T cell activation requires at least two signals from an antigen-presenting cell (APC) to become fully activated. The first one occurs on TCR engagement by the antigen-major histocompatibility complex (MHC) expressed by the APC, and the second one occurs on subsequent engagement of costimulatory molecules (Fig. 1). The most potent $\mathrm{T}$ cell costimulatory molecule in naïve T cells is CD28; its ligands CD80 and CD86 are present on APCs. These signals are transmitted to the nucleus of T cells, which results in the expression of activation markers at the cell surface, induction of cytokine secretion or cytotoxic function, cell proliferation, and differentiation into effector cells (55).
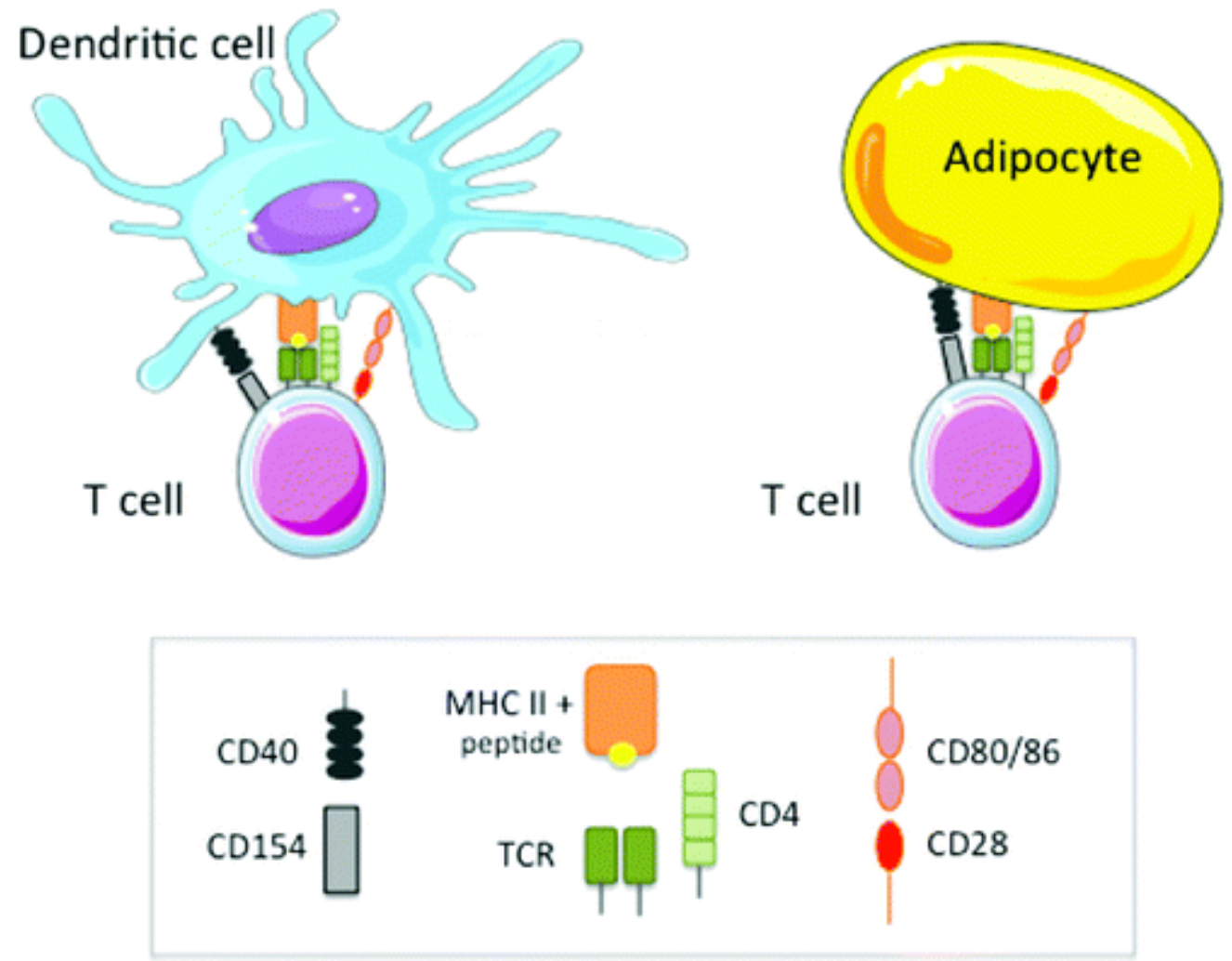

FIG. 1. Interactions between APC and T cells - a role for costismulatory molecules such as CD28 and CD154 molecules. Usually, professional APC such as dendritic cells via their MHC II molecules will present the antigen (peptide) to $\mathrm{CD} 4^{+} \mathrm{T}$ cells that induce the first signal via their TCR. However, the T cell activation requires a second signal induced by costimulatory molecules. In the early steps of costimulation, both CD154 (also called CD40 ligand) and CD28 play a critical role in this antigen-presentation-mediated $\mathrm{T}$ cell activation. In AT, similar activation steps occur with interactions between T cells and AT-resident DC, with not only macrophages but also adipocytes. As adipocytes could express MHC II, the 
CD28 (CD80 and CD86) and CD40 ligands, this cell type could be also considered a potential APC (see text). APC, antigen-presenting cell; AT, adipose tissues; MHC II, major histocompatibility complex class II; TCR, T cell antigen-specific receptor. To see this illustration in color, the reader is referred to the web version of this article at www.liebertpub.com/ars

There is strong evidence that $\mathrm{T}$ cell activation is induced by AT components. In fact, T cell division is induced by a contact between splenic $\mathrm{CD}^{+} \mathrm{T}$ cells and a cell extract of epididymal AT from DIO mice, but not with AT from lean mice (63). Some adipokines such as leptin promote naive $\mathrm{T}$ cell proliferation and cytokine production in pro-inflammatory $\mathrm{T}$ cells $(24$, 97). HFD contains high levels of triglycerides, which induce the intestinal absorption of peptide antigens. These food-derived antigens via these triglyceride carriers could be cleared in the AT to stimulate pro-inflammatory T cells $(24,28,83)$. Thus, in AT, gut-derived antigens can be presented to $\mathrm{T}$ cells to activate them and pro-inflammatory adipokines enhance this $\mathrm{T}$ cell activation.

Hypoxic conditions are detected during adipocyte hypertrophy, and hypoxia induces proinflammatory adipokine production associated with a $\mathrm{CD}^{+} \mathrm{T}$ cell infiltration in AT (75). These hypoxic conditions favor $\mathrm{CD}^{+} \mathrm{T}$ cell activation via the expression of hypoxiainducible factors in T cells (30). Moreover, this increase of hypoxia-inducible factors is required for IFN- $\gamma$ production and could be involved in a switch from regulatory to proinflammatory $\mathrm{T}$ cell status (53).

Taken together, DIO creates a context in AT that favors enhanced T cell activation, for instance through the production of food-derived antigens that can be presented to $\mathrm{T}$ cells by so-called "professional" APC such as AT dendritic cells (5) or both AT-anti- and -proinflammatory macrophages (15). It has also been suggested that adipocytes expressing both class II MHC molecules and the CD28 ligands CD80 (B7-1) and CD86 (B7-2) are considered as APC $(26,95)$. In addition, B7 (B7-1 and B7-2) molecules play an essential role in maintaining Treg homeostasis within AT, and the loss of B7 molecules exacerbates insulin resistance (99) and non-alcoholic steatohepatitis during obesity (12).

T cell activation (84) and Treg development (86) are reduced in lymphoid organs from CD28deficient $(C D 28 \mathrm{KO})$ mice. To directly evaluate the role of the $\mathrm{CD} 28, C D 28 \mathrm{KO}$ mice were analyzed during DIO (69). The loss of $C D 28$ was found to decrease both pathogenic T cells and Tregs levels without changing the numbers of macrophages within AT. CD28 KO epididymal fat was characterized by enlarged adipocytes and reduced levels of inflammatory cytokines, which were associated with a major hepatic phenotype, as the CD28 deficiency protects obese mice from liver steatosis (69).

Several signaling motifs have been identified in the cytoplasmic tail of CD28, and there is a large debate about how CD28 mediates the costimulatory signals $(7,35)$. A large number of experiments have been performed to assess the role of the cytoplasmic tail of CD28, including studies using primary $\mathrm{T}$ cells in transgenic ( $\mathrm{Tg}$ ) mice or retroviral reconstitution in the $C D 28$ deficient background $(7,64)$. Our group has generated a $C D 28$ gene targeted knock-in (KI) mouse strain lacking the cytoplasmic tail of CD28. Regulatory T cell homeostasis and T cell activation are altered in both $C D 28 \mathrm{KO}$ and $C D 28 \mathrm{KI}$ tailless mice. However, the presence of a CD28 molecule lacking its cytoplasmic tail is sufficient to induce some early activation events in T cells such as signaling events or expression of early activation markers (61). A loss of $C D 28$ results in protection from hepatic steatosis during DIO (69); we further analyzed 
the development of hepatic steatosis in DIO-CD28 KI tailless mice. An HFD-fed $C D 28 \mathrm{KI}$ cohort was included in the published study on DIO-CD28 KO mice (69), the results of which are shown next (Figs. 2-4).

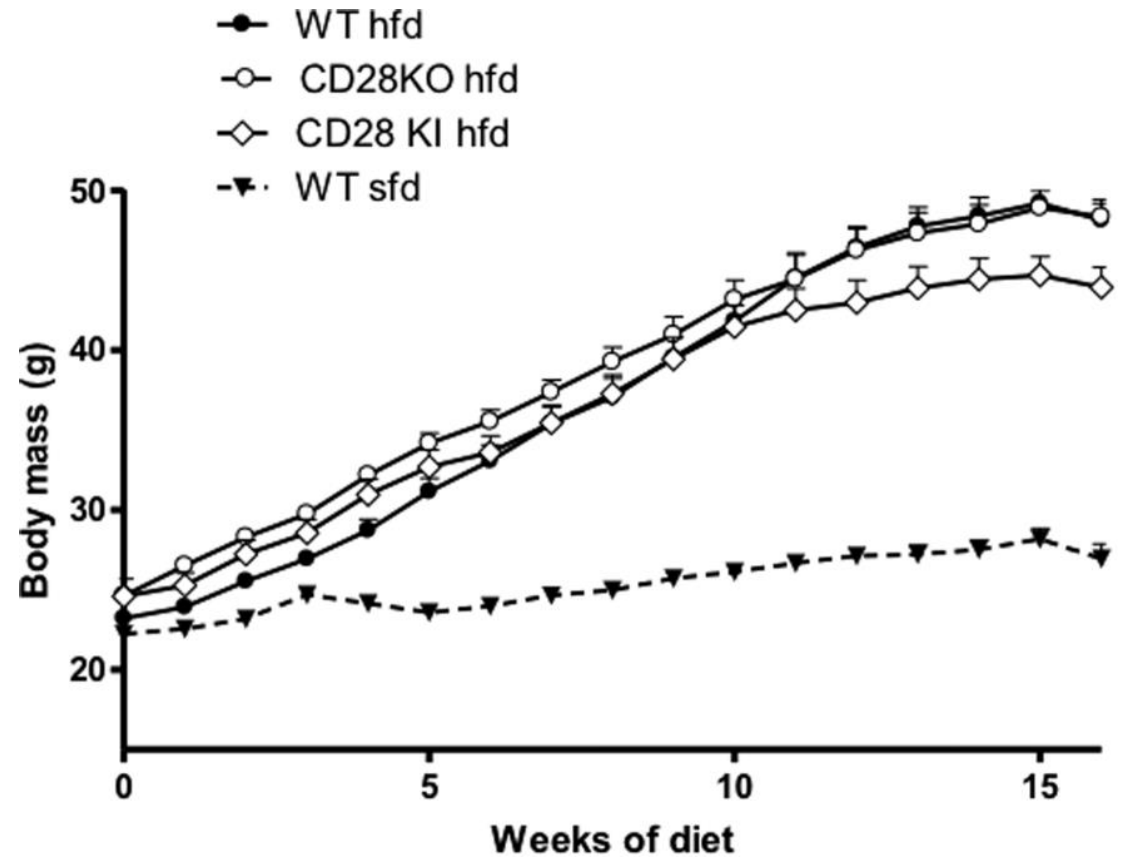

FIG. 2. Body mass gain. Male C57BL/6 and deficient mice were fed SFD or HFD (60\% fat) for 16 weeks. Body weight gain of HFD-fed WT (line, full circle), CD28KO (dotted line, open circle), and CD28KI mice (line, diamond) and of SFD-fed WT mice (line, triangle). HFD, high fat diet; KI, knock-in; SFD, standard fat diet; WT, wild-type. 

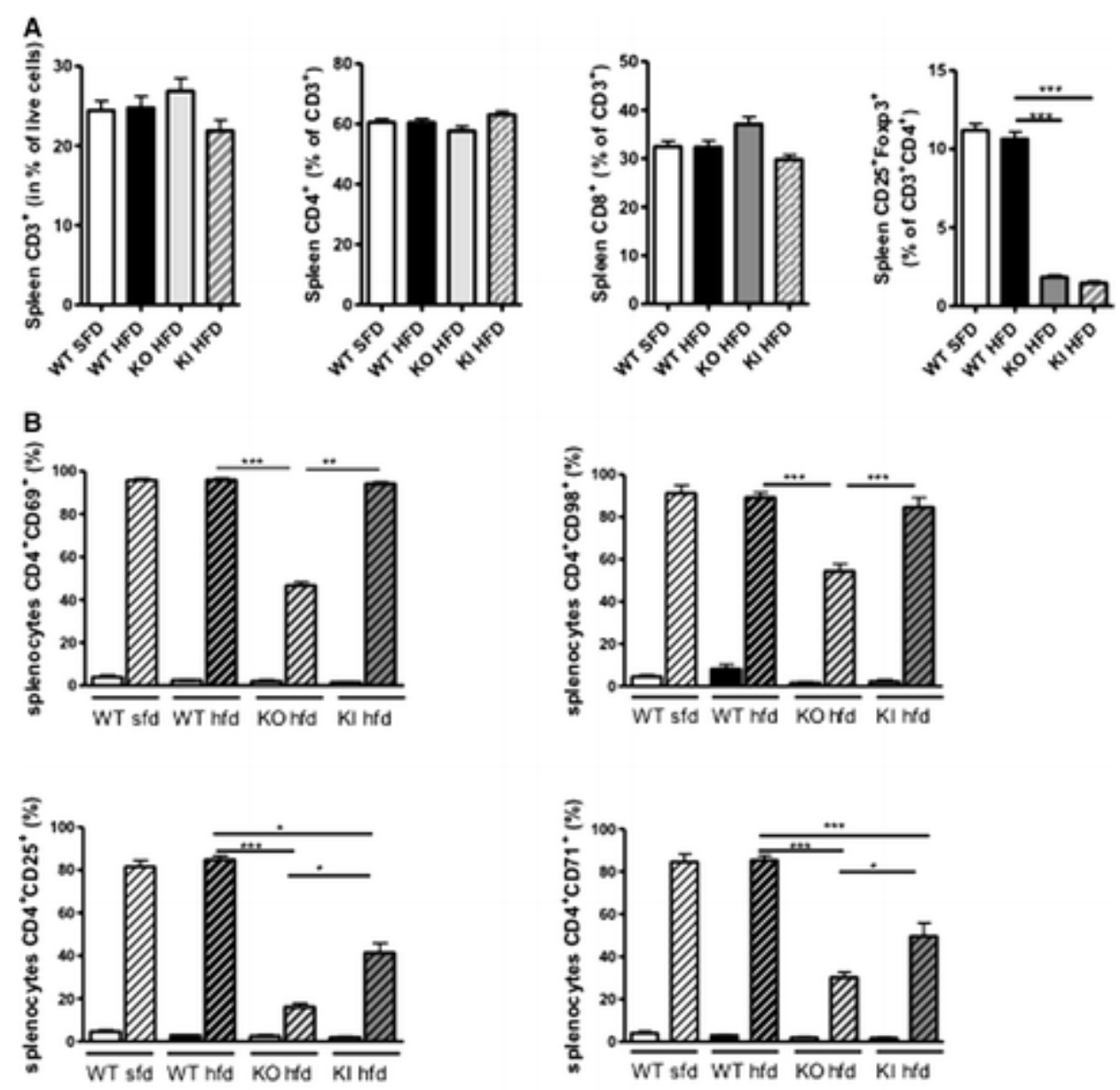

$\square$ Unstimulated $\mathrm{CD}^{*}$
ש ${ }^{*}$ 3/CD28 stimulated CD4*

FIG. 3. $C D 28 \mathrm{KO}$ mice but not $C D 28 \mathrm{KI}$ mice display a profound $\mathrm{T}$ cell activation defect. Males C57BL/6 and deficient mice were fed SFD or HFD (60\% fat) for 16 weeks. (A) Fluorescence-activated cell sorting analysis of the spleen cells. The fractions of $\mathrm{CD}^{+}, \mathrm{CD}^{+}$, $\mathrm{CD}^{+}$, and regulatory $\mathrm{T}$ cells $\left(\mathrm{CD} 4^{+} \mathrm{CD} 25^{+} \mathrm{FoxP} 3^{+}\right)$were determined. Data are expressed as mean \pm SEM in percentage of positive cells. (B) Fluorescence-activated cell sorting analysis of the $\mathrm{CD}^{+} \mathrm{T}$ cells splenocytes of WT and $C D 28$ genetically modified mice purified by negative selection and stimulated with Dynabeads Mouse T-Activator CD3/CD28 in 24-well round-bottom plates for 2 days. Data are expressed as mean \pm SEM in percentage of positive cells. $n=12-13$ per group, Kruskal-Wallis test (one-way ANOVA) with Dunn's Multiple Comparison, $* p<0.05,{ }^{* *} p<0.01$, and ${ }^{* * *} p<0.001$. KO, knock-out. 

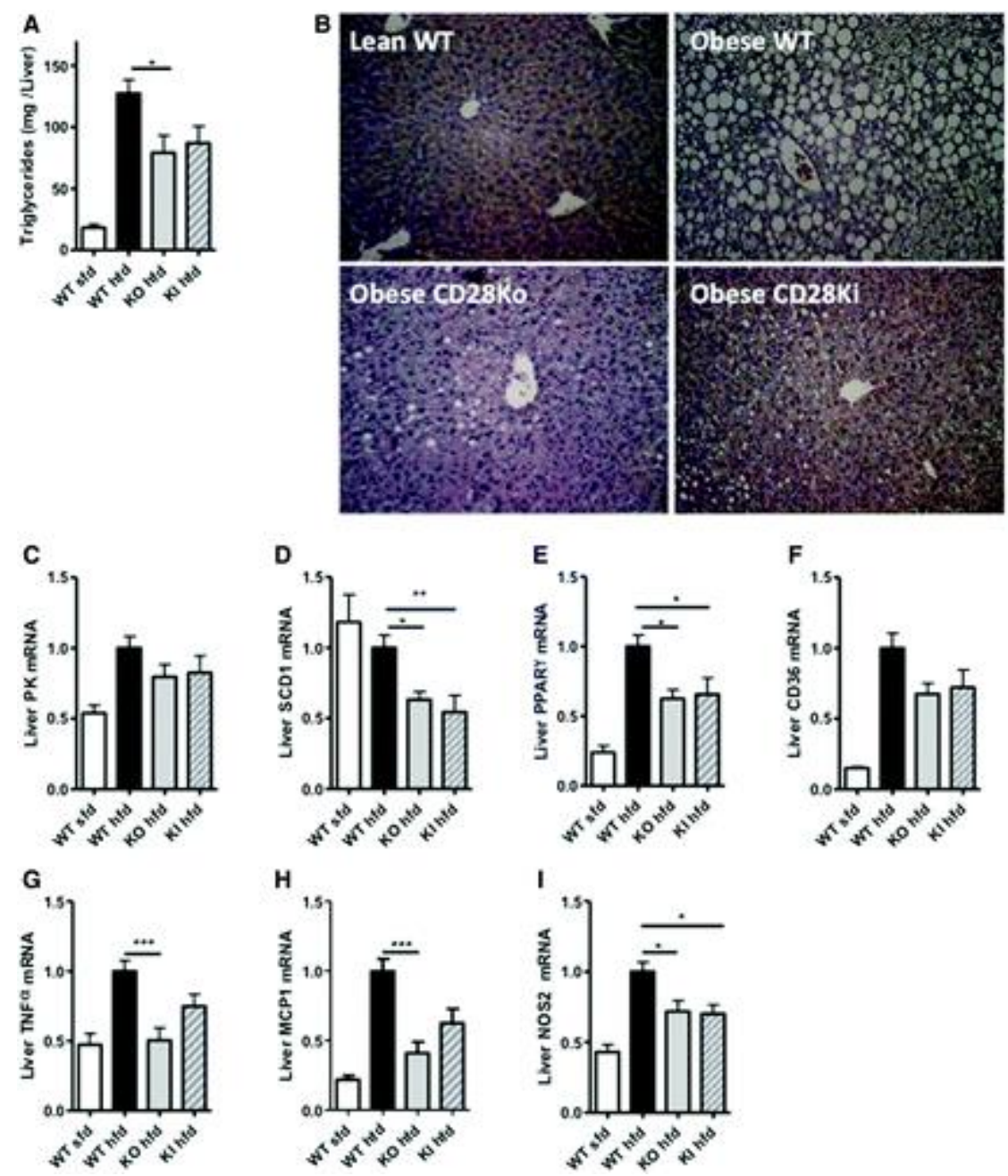

FIG. 4. Both $C D 28 \mathrm{KO}$ and $C D 28 \mathrm{KI}$ tailless mice are protected against liver fat accumulation. (A) Hepatic triglycerides content of WT and CD28 genetically modified mice. (B) H\&E-stained liver sections from WT and CD28 genetically modified mice. The lipid droplets appear as vacuoles in the H\&E-stained tissue slide $(\times 20)$. (C-I) Quantification of mRNA by RT-PCR in liver. mRNA expression was normalized to housekeeping $36 b 4$ RNA. $n=12-13$ per group, Kruskal-Wallis test (one-way ANOVA) with Dunn's Multiple Comparison, $* p<0.05, * * p<0.01$, and $* * * p<0.001$. H\&E, hematoxylin and eosin. To see this illustration in color, the reader is referred to the web version of this article at www.liebertpub.com/ars

CD28 KO, CD28 KI, and wild-type (WT) mice were fed with a standard fat diet (70\% kcal carbohydrate, $10 \% \mathrm{kcal}$ fat, $20 \% \mathrm{kcal}$ protein, $3.68 \mathrm{kcal} / \mathrm{g}$; Special Diets Services [SDS], Witham, United Kingdom) or an HFD (20\% kcal carbohydrate, $60 \%$ kcal fat, $20 \% \mathrm{kcal}$ protein, $5.13 \mathrm{kcal} / \mathrm{g}$; SDS) for 16 weeks starting at 8-10 weeks of age. Weight gain curves indicate that on HFD, $C D 28 \mathrm{KO}$ and $C D 28 \mathrm{KI}$ mice become obese with a similar profile than their WT counterpart (Fig. 2).

No major differences were observed in $\mathrm{T}$ cell number $\left(\mathrm{CD} 3^{+}, \mathrm{CD} 4^{+}\right.$, and $\mathrm{CD} 8^{+} \mathrm{T}$ cells $)$ in CD28 KO and KI spleens compared with WT mice, whereas Tregs levels were strongly reduced compared with WT mice (Fig. 3A). The effect of $C D 28$ alterations on activated T cell surface markers was then tested. Two days after in vitro stimulation with anti-CD3/CD28 
beads, CD69, CD98, CD25, and CD71 levels were strongly reduced in CD4 ${ }^{+} \mathrm{T}$ cells isolated from spleen of $C D 28 \mathrm{KO}$ compared with WT mice (Fig. 3B). Cell surface activation marker levels were much higher in CD28 KI splenocytes. The increased levels of CD69 and CD98 induced by CD3/CD28 stimulation were similar in CD28 KI and WT mice (Fig. 3B). Also, the induced expression of CD25 and CD71 was significantly higher in CD28 KI than in CD28 $\mathrm{KO}$ animals (Fig. 3B). These results indicate that T cell activation occurs in obese $C D 28 \mathrm{KI}$ mice but not in obese $C D 28 \mathrm{KO}$ mice. Thus, DIO-CD28 KO mice but not -CD28 KI mice display a profound $\mathrm{T}$ cell activation defect.

We then investigated the impact of $C D 28$ deficiencies on obesity-related inflammation. Both obese $C D 28 \mathrm{KO}$ and $C D 28 \mathrm{KI}$ mouse livers accumulated less triglycerides than obese WT mice (Fig. 4A, B). This decrease in fat accumulation was consistent with the lower levels observed of hepatic transcripts of genes involved in triglyceride accumulation (Fig. 4C-F). In addition, the livers of both obese $C D 28 \mathrm{KO}$ and $C D 28 \mathrm{KI}$ mice exhibited decreased levels of $T N F-\alpha, M C P-1$, and $i N O S$ mRNA, indicating a lower level of pro-inflammatory cytokines.

Finally, these results highlighted that $C D 28 \mathrm{KO}$ and $C D 28 \mathrm{KI}$ mice are protected against fat accumulation in liver, and that CD28 is strongly involved in lipid accumulation and inflammation in liver. As CD28 appears to be involved in the protection against bacterial infections in liver (42), it would be interesting to test this kind of immune response in the context of DIO. Taken together, CD28 deficiency creates a new pro-/anti-inflammatory balance in epididymal AT and liver, and it results in a protection against hepatic steatosis (69). The major findings from these $C D 28$-deficient mouse strains are summarized in Figure 5.

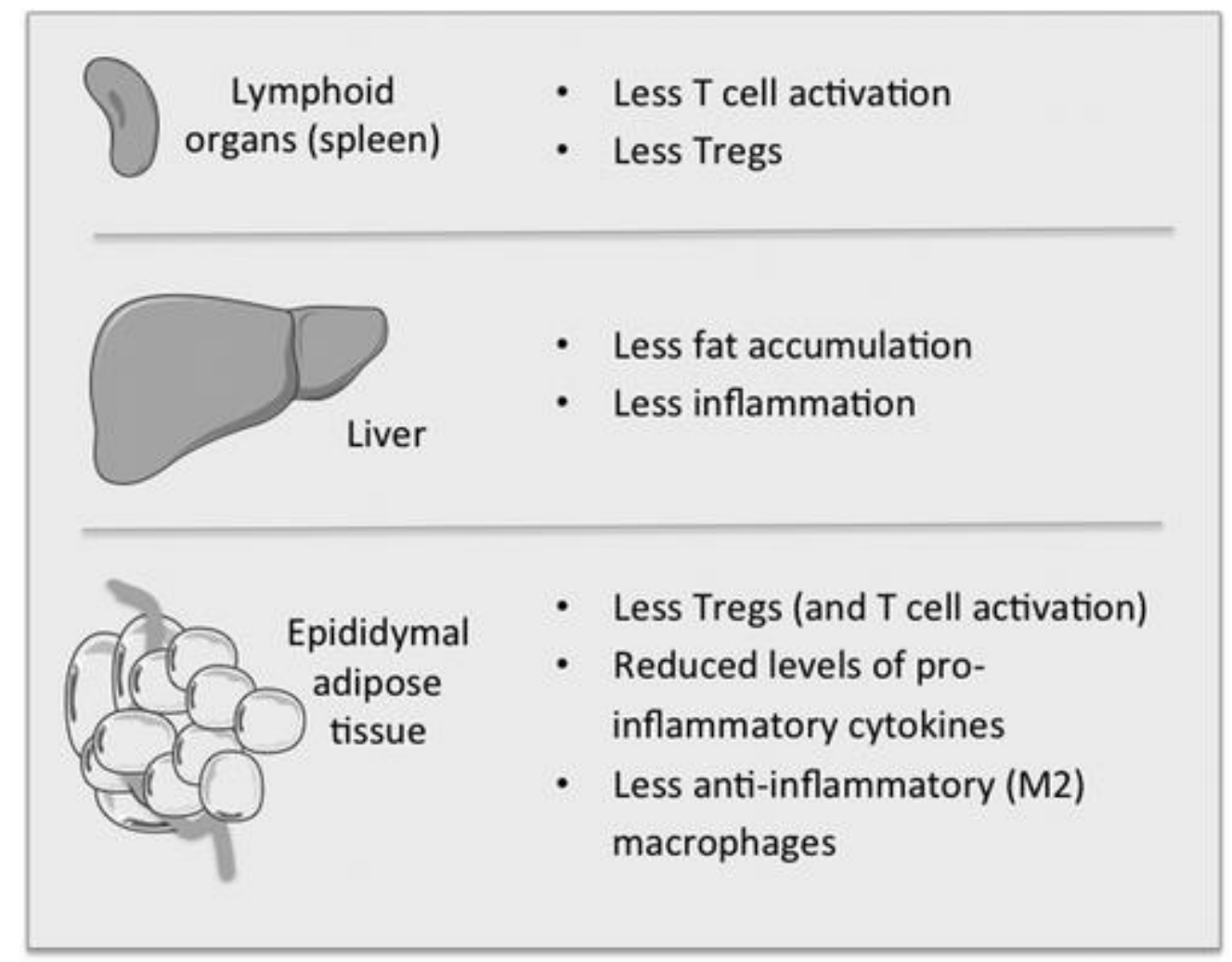

FIG. 5. Characteristics of DIO-CD28-deficient mice compared with WT mice in different tissues. DIO, diet-induced obesity. 
The role of other T cell cosignaling molecules in DIO has been assessed (82). Among the couples of ligand-receptor in T-APC interactions, the CD40/CD154 axis presents a therapeutic interest for AT inflammation. The pro-inflammatory CD40 molecule (also called TNF receptor superfamily member 5, CD40)/CD40 ligand (also called CD40L, CD154) pathway plays a role in the onset and maintenance of the inflammatory reaction. CD40 is expressed on adipocytes and contributes to obesity-related inflammation and insulin resistance. T lymphocytes expressing CD154 or releasing soluble CD154 (sCD154 produced by activated $\mathrm{CD} 4^{+} \mathrm{T}$ cells) (81) regulate adipocytokine production through both the release of soluble factors and heterotypic contact with adipocytes involving CD40. CD40 is involved in atherosclerosis $(1,80,88)$, and some data identify CD40/CD154 as a potential contributor to inflammation that is associated with obesity and its metabolic complications. Indeed, sCD154 levels are increased in obese $(27,79)$ and type 2 diabetic $(9,18,57)$ individuals. The expression of CD40 on AT cells, including adipocytes and immune cells, positively correlates with body mass index (68). CD40 ligation on adipocytes induces activation of proinflammatory signal transduction pathways, resulting in a generalized pro-inflammatory AT status. This is translated by an increased expression of cytokines and chemokines within the AT, including TNF- $\alpha$, IL-6, and MCP-1 (49, 59, 68). Furthermore, CD154 stimulation directly affects lipid metabolism in adipocytes (68). In vitro studies have identified a proinflammatory role of CD40-CD154 interactions in AT inflammation and metabolic deregulation; however, in vivo studies have highlighted a more complex dual function for the CD40-CD154 dyad. DIO-CD154 KO mice were protected against weight gain, AT inflammation, and hepatosteatosis (67). These results where mimicked in WT DIO mice treated with antagonistic CD154 monoclonal antibodies (mAbs). As mentioned earlier, other studies have demonstrated that mice treated with CD154 mAbs exhibit reduced weight gain, which was accompanied by a trend toward improved insulin resistance (60).

In contrast to $C D 154 \mathrm{KO}$ mice, $C D 40$-deficient mice on an HFD exhibit increased IR and hepatosteatosis, as well as enhanced AT inflammation $(14,40,94)$. In particular, AT inflammation of $C D 40 \mathrm{KO}$ obese mice correlated with elevated $\mathrm{CD} 8^{+} \mathrm{T}$ cells accompanied by higher numbers of M1 macrophages and increased expression of TNF- $\alpha$, IL-6, and IL-12 (14). These contradictory results can be explained by the involvement of various signaling pathways induced on CD40 activation. After CD154/CD40 ligation, CD40 recruits adaptor proteins, the TNF receptor-associated factors (TRAFs), to elicit intracellular signaling (32). CD40 contains a distal binding site for TRAF2, 3, and 5 and a proximal binding site for TRAF6. Mice with deficient CD40-TRAF2/3/5 signaling in $\mathrm{MHCII}^{+}$cells exhibited a similar phenotype in DIO as did CD40 KO mice. In contrast, mice with deficient CD40-TRAF6 signaling in $\mathrm{MHCII}^{+}$cells displayed no insulin resistance and showed a reduction in both AT inflammation and hepatosteatosis in DIO (14). In this way, it appears that the CD40TRAF2/3/5 signaling pathway protects against metabolic dysfunction and inflammation associated with obesity; conversely, the CD40-TRAF6 pathway contributes to the detrimental consequences of obesity. In conclusion, CD154 and CD40 present a dichotomy in their respective roles in the development of obesity, which is explained by the differential involvement of downstream signaling proteins. The improvement of insulin resistance by a specific CD40-TRAF6 inhibitor could represent a therapeutic breakthrough in the field of immunometabolism (14) and is a promising therapeutic strategy for obesity-related metabolic complications.

On T cell activation triggered by APC where TCR and adhesion molecules (such as costimulatory receptors) are engaged, naive $\mathrm{CD} 4^{+} \mathrm{T}$ cells differentiate into distinct $\mathrm{Th}$ lineages in the context of combinations of cytokines $(55,100)$. These soluble factors such as 
ILs (e.g., IL-2) are also important to sustain T cell activation. Via their pro- and antiinflammatory properties, the cytokines produced by $\mathrm{T}$ cells are determinant in the initiation of the AT inflammation. In this context, there are some dynamic interplays between $\mathrm{T}$ cells and adipocytes, not only via some direct cell-cell interactions (e.g., Fig. 1) but also by the fact that some adipocyte-derived hormones (adipokines) may be playing an important role in the regulation of T cell homeostasis (73). Among these adipokines, leptin is the most well studied in T cell biology (62). On leptin receptor (LepR) ligation, pro-inflammatory T cell responses are promoted (58) and Treg activity is reduced (25). Moreover, both $\mathrm{CD}^{+}{ }^{+} \mathrm{T}$ effector cells and Tregs can secrete leptin $(72,91)$. Leptin production by T cells could act as an autocrine and/or a paracrine signal to maintain leptin-associated $\mathrm{T}$ cell effects. In the context of AT inflammation, it will be of interest to further investigate the effects of the cocktail of adipokines on $\mathrm{T}$ cell subsets both in and outside the inflamed tissues.

\section{Concluding Remarks and Future Directions}

Several studies have demonstrated the role of T cells in the development of obesity. Moreover, adipose depots can be considered lymphoid organs where T cell-driven inflammation occurs. A T cell plasticity is observed in AT to adapt these cells to a fat environment, with the resident Tregs expressing high levels of PPAR- $\gamma(16)$. The understanding of the biology of T cells in AT will benefit from new single-cell experimental approaches. For instance, single-cell measurements of gene expression have allowed the identification of two subtypes of pro-inflammatory and anti-inflammatory cells within the Th17 cell population of a mouse model of multiple sclerosis (36). Moreover, extended flow cytometry analysis now allows a large panel of immune subsets to be analyzed in AT (socalled adipo-immune profiling), showing $\mathrm{T}$ cell variations between aged and DIO mice (4). This adipo-immune profiling could be further improved by adding several mAbs to detect other activation markers, phosphoproteins involved in immune cell signaling, and cytokines. This multi-dimensional single-cell analysis requires a technology that is able to analyze more than one hundred parameters at a single-cell level, such as mass cytometry (11). These singlecell technologies will be helpful to identify new immune subtypes involved in AT inflammation.

One of the goals of such studies is to target these pro-inflammatory T cells in AT, especially at the early steps of obesity. This is also important for the optimal treatment of human immunodeficiency virus (HIV) infections, as AT are known to constitute a reservoir for HIV (23). Cancer immunotherapy strategies targeting $\mathrm{T}$ cell immune checkpoints have been successful in clinical trials for different solid cancers such as melanoma (70). However, AT inflammation is an autoimmune disease for which the strategy would have to be different, for instance by targeting the CD28 T cell costimulatory molecule by blocking the interaction with its ligands (CD80 and CD86). A CTLA-4-Ig fusion protein is able to block the CD28-

CD80/CD86 interactions. A therapeutic version, Abatacept is currently used to treat rheumatoid arthritis. However, CTLA-4-Ig treatment is not associated with a decrease of AT inflammatory status during DIO $(60,69)$. This could result in the development of therapeutic strategies combining an inhibition with AT-pro-inflammatory T cells with a boost of regulatory $\mathrm{T}$ cells by targeting other $\mathrm{T}$ cell signaling molecules.

Moreover, other strategies, including nutritional options, could be tested using immunomodulators such as antioxidant/anti-inflammatory agents like micronutrients. Increased oxidative stress in AT is described during DIO (20), and the cellular reduction/oxidation (redox) status regulates T cell functions. For instance, low doses of 
reactive oxygen species such as hydrogen peroxide decrease the IFN- $\gamma$ secretion in activated pro-inflammatory T cells (47). Effects of compounds with a potent antioxidant activity should be further investigated to the revert pro-inflammatory/anti-inflammatory AT-resident T cells ratio during DIO (90).

Taken together, the T cell biology in AT should be further explored to define new potential therapeutic strategies for tissue inflammations and associated diseases.

\title{
Acknowledgments
}

The authors thank V. Ferrier-Depraetere (Institut Paoli-Calmettes) for a critical reading of the article. They are grateful to the CRCM animal facility for taking care of the mouse strain colonies and to the CRCM cytometry platform for FACS analysis. This work was supported by institutional grants from the Institut National de la Santé et de la Recherche Médicale, Centre National de la Recherche Scientifique, and Aix-Marseille Université to CRCM; from the "Société Francophone du Diabète," the European society of cardiology (M.P.); from the Institut National de la Recherche Agronomique, the "Fondation Coeur et Artères" (J.F.L.); and from the Fondation pour la Recherche Médicale (Equipe FRM DEQ20140329534) (J.A.N.). S.O.M. was supported by a fellowship from Aix-Marseille Université.

\author{
Abbreviations Used \\ APC antigen-presenting cell \\ AT adipose tissues \\ CCL C-C motif ligand \\ CD cluster differentiation \\ CTLA-4 cytotoxic T-lymphocyte-associated protein 4 \\ DIO diet-induced obesity \\ HFD high fat diet \\ HIV human immunodeficiency virus \\ $\mathrm{H} \& \mathrm{E} \quad$ hematoxylin and eosin \\ IFN interferon \\ IL interleukin \\ KI knock-in \\ KO knock-out \\ LepR leptin receptor \\ mAbs monoclonal antibodies \\ MHC major histocompatibility complex \\ PPAR peroxisome proliferator-activated receptors \\ RXR retinoic acid receptor \\ SDS Special Diets Services \\ SFD standard fat diet \\ TCR T cell antigen-specific receptor \\ TGF transforming growth factor \\ Th helper $\mathrm{T}$ cells \\ TNF tumor necrosis factor
}


TRAF TNF receptor-associated factor

Treg regulatory $\mathrm{T}$ cells

VAT visceral adipose tissue

VDR vitamin D receptor

VDRE vitamin D response element

WT wild-type

\section{References}

- 1 Aukrust P, Muller F, Ueland .d platelet involvement in the pathogenesis of acute coronary syndromes. Circulation 100: 614-620, 1999.

- 2 Baeke F, Korf H, Overbergh L, van Etten E, Verstuyf A, Gysemans C, and Mathieu

C . Human T lymphocytes are direct targets of 1,25-dihydroxyvitamin D3 in the immune system. J Steroid Biochem Mol Biol 121: 221-227, 2010.

- 3 Baeke F, Takiishi T, Korf H, Gysemans C, and Mathieu C . Vitamin D: modulator of the immune system. Curr Opin Pharmacol 10: 482-496, 2010.

- 4 Bapat SP , Myoung Suh J , Fang S , Liu S , Zhang Y, Cheng A, Zhou C, Liang Y, LeBlanc M , Liddle C, Atkins AR, Yu RT , Downes M, Evans RM, and Zheng Y .

Depletion of fat-resident T cells prevents age-associated insulin resistance. Nature 528: 137 $141,2015$.

- 5 Bertola A, Ciucci T, Rousseau D, Bourlier V, Duffaut C, Bonnafous S , BlinWakkach C , Anty R, Iannelli A, Gugenheim J , Tran A, Bouloumie A, Gual P, and Wakkach A . Identification of adipose tissue dendritic cells correlated with obesity-associated insulin-resistance and inducing Th17 responses in mice and patients. Diabetes 61: 22382247, 2012.

- 6 Bikle DD, Gee E, and Pillai S . Regulation of keratinocyte growth, differentiation, and vitamin D metabolism by analogs of 1,25-dihydroxyvitamin D. J Invest Dermatol 101: 713 $718,1993$.

- 7 Boomer JS and Green JM . An enigmatic tail of CD28 signaling. Cold Spring Harb Perspect Biol 2: a002436, 2010.

- 8 Bouillon R, Carmeliet G, Verlinden L, van Etten E, Verstuyf A, Luderer HF, Lieben L, Mathieu C, and Demay M . Vitamin D and human health: lessons from vitamin D receptor null mice. Endocr Rev 29: 726-776, 2008. • 9 Cabeza N , Li Z , Schulz C , Kremmer E, Massberg S , Bultmann A, and Gawaz M . Surface expression of collagen receptor Fc receptor-gamma/glycoprotein VI is enhanced on platelets in type 2 diabetes and mediates release of CD40 ligand and activation of endothelial cells. Diabetes 53: 2117-2121, 2004.

- 10 Carlberg C and Seuter S . A genomic perspective on vitamin D signaling. Anticancer Res 29: 3485-3493, 2009.

- 11 Chattopadhyay PK, Gierahn TM, Roederer M, and Love JC . Single-cell technologies for monitoring immune systems. Nat Immunol 15: 128-135, 2014.

- 12 Chatzigeorgiou A, Chung KJ , Garcia-Martin R, Alexaki VI, Klotzsche-von Ameln A, Phieler J , Sprott D , Kanczkowski W , Tzanavari T , Bdeir M , Bergmann S , Cartellieri M , Bachmann M, Nikolakopoulou P, Androutsellis-Theotokis A, Siegert G , Bornstein SR , Muders MH, Boon L, Karalis KP , Lutgens E , and Chavakis T . Dual role of B7 
costimulation in obesity-related nonalcoholic steatohepatitis and metabolic dysregulation.

Hepatology 60: 1196-1210, 2014.

- 13 Chatzigeorgiou A, Karalis KP, Bornstein SR, and Chavakis T . Lymphocytes in obesity-related adipose tissue inflammation. Diabetologia 55: 2583-2592, 2012.

- 14 Chatzigeorgiou A , Seijkens T , Zarzycka B , Engel D , Poggi M, van den Berg S , Soehnlein O, Winkels H, Beckers L, Lievens D, Driessen A, Kusters P , Biessen E, Garcia-Martin R, Klotzsche-von Ameln A , Gijbels M, Noelle R , Boon L , Hackeng T , Schulte KM , Xu A, Vriend G, Nabuurs S, Chung KJ , Willems van Dijk K, Rensen PC , Gerdes N, de Winther M, Block NL, Schally AV , Weber C , Bornstein SR , Nicolaes G, Chavakis T, and Lutgens E . Blocking CD40-TRAF6 signaling is a therapeutic target in obesity-associated insulin resistance. Proc Natl Acad Sci U S A 111: 2686-2691, 2014.

- 15 Cho KW, Morris DL, DelProposto JL, Geletka L, Zamarron B , Martinez-Santibanez G , Meyer KA, Singer K, O'Rourke RW , and Lumeng CN . An MHC II-dependent activation loop between adipose tissue macrophages and CD4+ T cells controls obesityinduced inflammation. Cell Rep 9: 605-617, 2014.

- 16 Cipolletta D , Feuerer M, Li A, Kamei N, Lee J , Shoelson SE, Benoist C, and Mathis D . PPAR-[ggr] is a major driver of the accumulation and phenotype of adipose tissue Treg cells. Nature 486: 549-553, 2012.

- 17 Cipolletta D, Kolodin D, Benoist C , and Mathis D . Tissular T(regs): a unique population of adipose-tissue-resident Foxp3+CD4+ T cells that impacts organismal metabolism. Semin Immunol 23: 431-437, 2011.

- 18 Cipollone F, Chiarelli F, Davi G , Ferri C , Desideri G, Fazia M, Iezzi A, Santilli F, Pini B , Cuccurullo C, Tumini S , Del Ponte A, Santucci A, Cuccurullo F, and Mezzetti A . Enhanced soluble CD40 ligand contributes to endothelial cell dysfunction in vitro and monocyte activation in patients with diabetes mellitus: effect of improved metabolic control.

Diabetologia 48: 1216-1224, 2005.

- 19 Clark RB , Bishop-Bailey D, Estrada-Hernandez T, Hla T , Puddington L, and Padula SJ . The nuclear receptor PPAR gamma and immunoregulation: PPAR gamma mediates inhibition of helper T cell responses. J Immunol 164: 1364-1371, 2000.

- 20 Curtis JM, Grimsrud PA, Wright WS , Xu X, Foncea RE, Graham DW , Brestoff JR , Wiczer BM, Ilkayeva O, Cianflone K, Muoio DE , Arriaga EA, and Bernlohr DA .

Downregulation of adipose glutathione S-transferase A4 leads to increased protein carbonylation, oxidative stress, and mitochondrial dysfunction. Diabetes 59: 1132-1142, 2010.

- 21 Dalmas E, Clement K, and Guerre-Millo M . Defining macrophage phenotype and function in adipose tissue. Trends Immunol 32: 307-314, 2011.

- 22 Dalmas E, Venteclef N, Caer C, Poitou C, Cremer I, Aron-Wisnewsky J , LacroixDesmazes S , Bayry J , Kaveri SV , Clement K, Andre S , and Guerre-Millo M . T cellderived IL-22 amplifies IL-1beta-driven inflammation in human adipose tissue: relevance to obesity and type 2 diabetes. Diabetes 63: 1966-1977, 2014.

- 23 Damouche A, Lazure T, Avettand-Fenoel V , Huot N, Dejucq-Rainsford N, Satie AP, Melard A, David L, Gommet C, Ghosn J, Noel N, Pourcher G, Martinez V , Benoist S , Bereziat V , Cosma A, Favier B , Vaslin B , Rouzioux C , Capeau J , Muller-Trutwin M , Dereuddre-Bosquet N, Le Grand R, Lambotte O, and Bourgeois C . Adipose tissue is a neglected viral reservoir and an inflammatory site during chronic HIV and SIV infection.

PLoS Pathog 11: e1005153, 2015.

- 24 De Rosa V, Galgani M , Santopaolo M, Colamatteo A, Laccetti R , and Matarese G . Nutritional control of immunity: balancing the metabolic requirements with an appropriate immune function. Semin Immunol 27: 300-309, 2015. 
- 25 De Rosa V , Procaccini C, Cali G, Pirozzi G, Fontana S , Zappacosta S, La Cava A, and Matarese $\mathrm{G}$. A key role of leptin in the control of regulatory $\mathrm{T}$ cell proliferation.

Immunity 26: 241-255, 2007.

- 26 Deng T, Lyon CJ , Minze LJ , Lin J, Zou J, Liu JZ, Ren Y, Yin Z, Hamilton DJ , Reardon PR, Sherman V , Wang HY, Phillips KJ , Webb P, Wong STC, Wang R-F , and Hsueh WA . Class II major histocompatibility complex plays an essential role in obesityinduced adipose inflammation. Cell Metab 17: 411-422, 2013.

- 27 Desideri G and Ferri C . Effects of obesity and weight loss on soluble CD40L levels. JAMA 289: 1781-1782, 2003.

- 28 DiSpirito JR and Mathis D . Immunological contributions to adipose tissue homeostasis. Semin Immunol 27: 315-321, 2015.

- 29 Dobrian AD, Galkina EV , Ma Q, Hatcher M, Aye SM, Butcher MJ , Ma K, Haynes BA, Kaplan MH , and Nadler JL . STAT4 deficiency reduces obesity-induced insulin resistance and adipose tissue inflammation. Diabetes 62: 4109-4121, 2013.

- 30 Doedens AL, Phan AT, Stradner MH , Fujimoto JK, Nguyen JV, Yang E, Johnson RS , and Goldrath AW . Hypoxia-inducible factors enhance the effector responses of CD8(+) T cells to persistent antigen. Nat Immunol 14: 1173-1182, 2013.

- 31 Duffaut C, Zakaroff-Girard A, Bourlier V, Decaunes P, Maumus M, Chiotasso P, Sengenes C , Lafontan M, Galitzky J , and Bouloumie A . Interplay between human adipocytes and T lymphocytes in obesity: CCL20 as an adipochemokine and T lymphocytes as lipogenic modulators. Arterioscler Thromb Vasc Biol 29: 1608-1614, 2009.

- 32 Engel D, Seijkens T, Poggi M, Sanati M, Thevissen L, Beckers L, Wijnands E, Lievens D, and Lutgens E. The immunobiology of CD154-CD40-TRAF interactions in atherosclerosis. Semin Immunol 21: 308-312, 2009.

- 33 Fabbrini E, Cella M, McCartney SA, Fuchs A, Abumrad NA, Pietka TA, Chen Z, Finck BN , Han DH, Magkos F, Conte C, Bradley D, Fraterrigo G, Eagon JC , Patterson BW , Colonna M , and Klein S . Association between specific adipose tissue CD4+ T-cell populations and insulin resistance in obese individuals. Gastroenterology 145: 366-374 e1e3, 2013.

- 34 Feuerer M, Herrero L, Cipolletta D, Naaz A, Wong J , Nayer A, Lee J , Goldfine AB , Benoist C, Shoelson S , and Mathis D . Lean, but not obese, fat is enriched for a unique population of regulatory $T$ cells that affect metabolic parameters. Nat Med 15: 930-939, 2009.

- 35 Garcon F, Ghiotto M, Gerard A, Yang WC, Olive D, and Nunes JA . The SH3 domain of Tec kinase is essential for its targeting to activated CD28 costimulatory molecule.

Eur J Immunol 34: 1972-1980, 2004.

- 36 Gaublomme JT, Yosef N, Lee Y, Gertner RS , Yang LV, Wu C, Pandolfi PP , Mak T , Satija R, Shalek AK, Kuchroo VK, Park H , and Regev A . Single-cell genomics unveils critical regulators of Th17 cell pathogenicity. Cell 163: 1400-1412, 2015.

- 37 Gerriets VA and MacIver NJ . Role of T cells in malnutrition and obesity. Front Immunol 5: 379, 2014.

- 38 Gregor MF and Hotamisligil GS . Inflammatory mechanisms in obesity. Annu Rev Immunol 29: 415-445, 2011.

- 39 Griffith JW, Sokol CL, and Luster AD . Chemokines and chemokine receptors: positioning cells for host defense and immunity. Annu Rev Immunol 32: 659-702, 2014. - 40 Guo CA , Kogan S, Amano SU, Wang M, Dagdeviren S , Friedline RH, Aouadi M , Kim JK, and Czech MP . CD40 deficiency in mice exacerbates obesity-induced adipose tissue inflammation, hepatic steatosis, and insulin resistance. Am J Physiol Endocrinol Metab 304: E951-E963, 2013. 
- 41 Haffner S and Taegtmeyer H . Epidemic obesity and the metabolic syndrome.

Circulation 108: 1541-1545, 2003.

- 42 Honstettre A, Meghari S, Nunes JA, Lepidi H, Raoult D, Olive D, and Mege JL.

Role for the CD28 molecule in the control of Coxiella burnetii infection. Infect Immun 74:

1800-1808, 2006.

- 43 Issa LL, Leong GM, and Eisman JA . Molecular mechanism of vitamin D receptor action. Inflamm Res 47: 451-475, 1998.

- 44 Joshi S, Pantalena LC, Liu XK, Gaffen SL, Liu H, Rohowsky-Kochan C, Ichiyama K, Yoshimura A, Steinman L, Christakos S , and Youssef S . 1,25-dihydroxyvitamin D( $\underline{3})$ ameliorates Th17 autoimmunity via transcriptional modulation of interleukin-17A. Mol Cell Biol 31: 3653-3669, 2011.

- 45 Karkeni E, Marcotorchino J , Tourniaire F, Astier J , Peiretti F, Darmon P, and Landrier JF . Vitamin D limits chemokine expression in adipocytes and macrophage migration in vitro and in male mice. Endocrinology 156: 1782-1793, 2015.

- 46 Karlsson EA and Beck MA . The burden of obesity on infectious disease. Exp Biol Med 235: 1412-1424, 2010.

- 47 Kesarwani P, Murali AK, Al-Khami AA, and Mehrotra S . Redox regulation of T-cell function: from molecular mechanisms to significance in human health and disease. Antioxid Redox Signal 18: 1497-1534, 2013.

- 48 Khan IM , Dai Perrard XY, Perrard JL, Mansoori A, Smith CW , Wu H, and Ballantyne CM . Attenuated adipose tissue and skeletal muscle inflammation in obese mice with combined CD4+ and CD8+ T cell deficiency. Atherosclerosis 233: 419-428, 2014.

- 49 Klein D , Timoneri F , Ichii H , Ricordi C , and Pastori RL . CD40 activation in human pancreatic islets and ductal cells. Diabetologia 51: 1853-1861, 2008.

- 50 Kratz M , Coats BR, Hisert KB, Hagman D, Mutskov V , Peris E, Schoenfelt KQ, Kuzma JN , Larson I , Billing PS , Landerholm RW , Crouthamel M , Gozal D , Hwang S , Singh PK, and Becker L . Metabolic dysfunction drives a mechanistically distinct proinflammatory phenotype in adipose tissue macrophages. Cell Metab 20: 614-625, 2014.

- 51 Landrier JF, Karkeni E, Marcotorchino J , Bonnet L, and Tourniaire F . Vitamin D modulates adipose tissue biology: possible consequences for obesity? Proc Nutr Soc 75: 3846, 2016.

- 52 Landrier JF, Marcotorchino J , and Tourniaire F . Lipophilic micronutrients and adipose tissue biology. Nutrients 4: 1622-1649, 2012.

- 53 Lee JH, Elly C, Park Y, and Liu YC . E3 ubiquitin ligase VHL regulates hypoxiainducible factor-1alpha to maintain regulatory $\mathrm{T}$ cell stability and suppressive capacity.

Immunity 42: 1062-1074, 2015.

- 54 Lemire JM , Adams JS , Kermani-Arab V, Bakke AC, Sakai R, and Jordan SC . 1,25Dihydroxyvitamin D3 suppresses human T helper/inducer lymphocyte activity in vitro. J Immunol 134: 3032-3035, 1985.

- 55 Lenschow DJ , Walunas TL, and Bluestone JA . CD28/B7 system of T cell costimulation. Annu Rev Immunol 14: 233-258, 1996.

- 56 Lifshitz F and Lifshitz JZ . Globesity: the root causes of the obesity epidemic in the USA and now worldwide. Pediatr Endocrinol Rev 12: 17-34, 2014.

- 57 Lim HS, Blann AD, and Lip GY . Soluble CD40 ligand, soluble P-selectin, interleukin6, and tissue factor in diabetes mellitus: relationships to cardiovascular disease and risk factor intervention. Circulation 109: 2524-2528, 2004.

- 58 Lord GM, Matarese G, Howard JK, Baker RJ, Bloom SR, and Lechler RI . Leptin modulates the T-cell immune response and reverses starvation-induced immunosuppression.

Nature 394: 897-901, 1998. 
- 59 Missiou A, Wolf D , Platzer I, Ernst S , Walter C, Rudolf P , Zirlik K, Kostlin N, Willecke FK, Munkel C, Schonbeck U, Libby P, Bode C, Varo N , and Zirlik A . CD40L induces inflammation and adipogenesis in adipose cells - a potential link between metabolic and cardiovascular disease. Thromb Haemost 103: 788-796, 2010.

- 60 Montes VN, Turner MS , Subramanian S, Ding Y, Hayden-Ledbetter M, Slater S, Goodspeed L, Wang S , Omer M , Den Hartigh LJ , Averill MM , O'Brien KD , Ledbetter J , and Chait A . T cell activation inhibitors reduce CD8+ T cell and pro-inflammatory macrophage accumulation in adipose tissue of obese mice. PLoS One 8: e67709, 2013.

- 61 Morin SO, Giroux V , Favre C, Bechah Y, Auphan-Anezin N, Roncagalli R, Mege JL, Olive D, Malissen M, and Nunes JA . In the absence of its cytosolic domain, the CD28 molecule still contributes to T cell activation. Cell Mol Life Sci 72: 2739-2748, 2015.

- 62 Naylor C , Petri WAJr. Leptin regulation of immune responses. Trends Mol Med 22: 88-98, 2016.

- 63 Nishimura S, Manabe I, Nagasaki M, Eto K, Yamashita H, Ohsugi M , Otsu M, Hara K, Ueki K, Sugiura S , Yoshimura K, Kadowaki T , and Nagai R . CD8+ effector T cells contribute to macrophage recruitment and adipose tissue inflammation in obesity. Nat Med 15: 914-920, 2009.

- 64 Ogawa S, Watanabe M, Sakurai Y, Inutake Y, Watanabe S, Tai X, and Abe R. CD28 signaling in primary CD4(+) T cells: identification of both tyrosine phosphorylationdependent and phosphorylation-independent pathways. Int Immunol 25: 671-681, 2013.

- 65 Osborn O and Olefsky JM . The cellular and signaling networks linking the immune system and metabolism in disease. Nat Med 18: 363-374, 2012.

- 66 Plum LA and DeLuca HF . Vitamin D, disease and therapeutic opportunities. Nat Rev Drug Discov 9: 941-955, 2010.

- 67 Poggi M, Engel D, Christ A, Beckers L, Wijnands E, Boon L, Driessen A, Cleutjens J, Weber C, Gerdes N, and Lutgens E . CD40L deficiency ameliorates adipose tissue inflammation and metabolic manifestations of obesity in mice. Arterioscler Thromb Vasc Biol 31: 2251-2260, 2011.

- 68 Poggi M , Jager J , Paulmyer-Lacroix O , Peiretti F, Gremeaux T, Verdier M, Grino M , Stepanian A, Msika S , Burcelin R, de Prost D, Tanti JF, and Alessi MC . The inflammatory receptor CD40 is expressed on human adipocytes: contribution to crosstalk between lymphocytes and adipocytes. Diabetologia 52: 1152-1163, 2009.

- 69 Poggi M , Morin SO, Bastelica D, Govers R, Canault M, Bernot D, Georgelin O, Verdier M, Burcelin R, Olive D, Alessi MC, Peiretti F, and Nunes JA . CD28 deletion improves obesity-induced liver steatosis but increases adiposity in mice. Int J Obes (Lond) 39: 977-985, 2015.

- 70 Postow MA, Chesney J , Pavlick AC, Robert C, Grossmann K, McDermott D, Linette GP , Meyer N, Giguere JK, Agarwala SS , Shaheen M , Ernstoff MS , Minor D, Salama AK, Taylor M, Ott PA, Rollin LM , Horak C , Gagnier P, Wolchok JD, and Hodi FS . Nivolumab and ipilimumab versus ipilimumab in untreated melanoma. N Engl J Med 372: 2006-2017, 2015.

- 71 Prietl B , Treiber G, Pieber TR, and Amrein K . Vitamin D and immune function. Nutrients 5: 2502-2521, 2013.

- 72 Procaccini C, De Rosa V , Galgani M, Abanni L, Cali G, Porcellini A, Carbone F , Fontana S, Horvath TL, La Cava A, and Matarese G . An oscillatory switch in mTOR kinase activity sets regulatory T cell responsiveness. Immunity 33: 929-941, 2010.

- 73 Procaccini C, De Rosa V , Galgani M, Carbone F, La Rocca C, Formisano L, and Matarese $\mathrm{G}$. Role of adipokines signaling in the modulation of T cells function. Front Immunol 4: 332, 2013. 
- 74 Provvedini DM, Tsoukas CD , Deftos LJ , and Manolagas SC . 1,25-dihydroxyvitamin D3 receptors in human leukocytes. Science 221: 1181-1183, 1983. 75 Rausch ME,

Weisberg S , Vardhana P , and Tortoriello DV . Obesity in C57BL/6J mice is characterized by adipose tissue hypoxia and cytotoxic T-cell infiltration. Int J Obes 32: 451-463, 2008.

- 76 Renehan AG, Zwahlen M , and Egger M . Adiposity and cancer risk: new mechanistic insights from epidemiology. Nat Rev Cancer 15: 484-498, 2015.

- 77 Rocha VZ, Folco EJ , Sukhova G, Shimizu K, Gotsman I, Vernon AH, and Libby P . Interferon-gamma, a Th1 cytokine, regulates fat inflammation: a role for adaptive immunity in obesity. Circ Res 103: 467-476, 2008.

- 78 Ruhl R and Landrier JF . Dietary regulation of adiponectin by direct and indirect lipidactivators of nuclear hormone receptors. Mol Nutr Food Res 60: 175-184, 2016.

- 79 Santilli F , Basili S , Ferroni P, and Davi G . CD40/CD40L system and vascular disease. Intern Emerg Med 2: 256-268, 2007.

- 80 Schonbeck U and Libby P . CD40 signaling and plaque instability. Circ Res 89: 1092$1103,2001$.

- 81 Schonbeck U and Libby P. The CD40/CD154 receptor/ligand dyad. Cell Mol Life Sci 58: 4-43, 2001.

- 82 Seijkens T, Kusters P, Chatzigeorgiou A, Chavakis T, and Lutgens E . Immune cell crosstalk in obesity: a key role for costimulation? Diabetes 63: 3982-3991, 2014.

- 83 Sell H , Habich C, and Eckel J . Adaptive immunity in obesity and insulin resistance.

Nat Rev Endocrinol 8: 709-716, 2012.

- 84 Shahinian A, Pfeffer K, Lee KP, Kundig TM, Kishihara K, Wakeham A, Kawai K, Ohashi PS , Thompson CB , and Mak TW . Differential T cell costimulatory requirements in CD28-deficient mice. Science 261: 609-612, 1993.

- 85 Shi H, Kokoeva MV , Inouye K, Tzameli I, Yin H, and Flier JS . TLR4 links innate immunity and fatty acid-induced insulin resistance. J Clin Invest 116: 3015-3025, 2006.

- 86 Tai X, Cowan M, Feigenbaum L, and Singer A . CD28 costimulation of developing thymocytes induces Foxp3 expression and regulatory $\mathrm{T}$ cell differentiation independently of interleukin 2. Nat Immunol 6: 152-162, 2005.

- 87 Tourniaire F, Romier-Crouzet B , Lee JH, Marcotorchino J , Gouranton E, Salles J , Malezet C, Astier J , Darmon P, Blouin E, Walrand S, Ye J , and Landrier JF . Chemokine expression in inflamed adipose tissue is mainly mediated by NF-kappaB. PLoS One 8: e66515, 2013.

- 88 Varo N, Vicent D, Libby P, Nuzzo R, Calle-Pascual AL, Bernal MR, FernandezCruz A, Veves A, Jarolim P, Varo JJ , Goldfine A, Horton E, and Schonbeck U . Elevated plasma levels of the atherogenic mediator soluble CD40 ligand in diabetic patients: a novel target of thiazolidinediones. Circulation 107: 2664-2669, 2003.

- 89 Versini M, Jeandel PY, Rosenthal E, and Shoenfeld Y . Obesity in autoimmune diseases: not a passive bystander. Autoimmun Rev 13: 981-1000, 2014.

- 90 Vujicic M, Nikolic I, Kontogianni VG, Saksida T, Charisiadis P, Orescanin-Dusic Z, Blagojevic D, Stosic-Grujicic S, Tzakos AG, and Stojanovic I . Methanolic extract of Origanum vulgare ameliorates type 1 diabetes through antioxidant, anti-inflammatory and anti-apoptotic activity. Br J Nutr 113: 770-782, 2015.

- 91 Wang S , Baidoo SE, Liu Y, Zhu C, Tian J , Ma J , Tong J , Chen J , Tang X, Xu H , and $\mathrm{Lu} \mathrm{L}$. T cell-derived leptin contributes to increased frequency of T helper type 17 cells in female patients with Hashimoto's thyroiditis. Clin Exp Immunol 171: 63-68, 2013.

- 92 Weisberg SP, McCann D, Desai M, Rosenbaum M, Leibel RL, and Ferrante AWJr. Obesity is associated with macrophage accumulation in adipose tissue. J Clin Invest 112: 1796-1808, 2003. 
- 93 Winer S, Chan Y, Paltser G, Truong D, Tsui H, Bahrami J, Dorfman R, Wang Y, Zielenski J , Mastronardi F, Maezawa Y, Drucker DJ , Engleman E , Winer D, and Dosch HM . Normalization of obesity-associated insulin resistance through immunotherapy. Nat Med 15: 921-929, 2009.

- 94 Wolf D, Jehle F, Michel NA, Bukosza EN, Rivera J , Chen YC, Hoppe N, Dufner B , Rodriguez AO, Colberg C, Nieto L, Rupprecht B , Wiedemann A, Schulte L, Peikert A , Bassler N , Lozhkin A, Hergeth SP, Stachon P, Hilgendorf I, Willecke F, von Zur Muhlen C, von Elverfeldt D , Binder CJ , Aichele P, Varo N, Febbraio MA , Libby P, Bode C, Peter K , and Zirlik A . Coinhibitory suppression of T cell activation by CD40 protects against obesity and adipose tissue inflammation in mice. Circulation 129: 2414-2425, 2014.

- 95 Xiao L, Yang X, Lin Y, Li S , Jiang J , Qian S, Tang Q, He R , and Li X . Large adipocytes function as antigen-presenting cells to activate CD4 $\mathrm{T}$ cells via upregulating MHCII in obesity. Int J Obes 40: 112-120, 2016.

- 96 Xu H , Barnes GT, Yang Q, Tan G, Yang D, Chou CJ , Sole J, Nichols A, Ross JS , Tartaglia LA, and Chen $\mathrm{H}$. Chronic inflammation in fat plays a crucial role in the development of obesity-related insulin resistance. J Clin Invest 112: 1821-1830, 2003.

- 97 Yu Y , Liu Y, Shi FD, Zou H , Matarese G, and La Cava A . Cutting edge: leptininduced RORgammat expression in CD4+ T cells promotes Th17 responses in systemic lupus erythematosus. J Immunol 190: 3054-3058, 2013.

- 98 Zeng $\mathrm{H}$ and Chi $\mathrm{H}$. Metabolic control of regulatory $\mathrm{T}$ cell development and function. Trends Immunol 36: 3-12, 2015.

- 99 Zhong J, Rao X, Braunstein Z, Taylor A, Narula V , Hazey J , Mikami D, Needleman B , Rutsky J , Sun Q, Deiuliis JA, Satoskar AR , and Rajagopalan S . T-cell costimulation protects obesity-induced adipose inflammation and insulin resistance. Diabetes 63: 12891302, 2014.

- 100 Zhu J , Yamane H, and Paul WE . Differentiation of effector CD4 T cell populations (*). Annu Rev Immunol 28: 445-489, 2010. 